\title{
Renal Countercurrent System: Role of Collecting Duct Convergence and Pelvic Urea Predicted from a Mathematical Model*
}

Peter Lory ${ }^{1 * *}$, Albert Gilg ${ }^{1}$, and Michael Horster ${ }^{2}$

1 Technische Universität München, Institut für Mathematik, D-8000 München, Federal Republic of Germany

${ }^{2}$ Universität München, Physiologisches Institut, D-8000 München, Federal Republic of Germany

\begin{abstract}
A differential equation model of the renal countercurrent system has been developed and physiological data from nephron segments were incorporated together with recently suggested urea recycling from renal pelvis to inner medulla and, particularly, an exponential reduction in the number of collecting tubules towards the renal papilla. The role of these features for the countercurrent concentrating mechanism has been studied by simulation runs. The computations, using the multiple shooting method, provide predictions about concentration profiles for salt and urea in tubes (nephron segments) and in the central core along the entire medullary countercurrent system. The results indicate that this model, without active salt or urea transport in the inner medulla, yields concentration gradients along the medullary axis compatible with those measured in the tissue.
\end{abstract}

Key words: Kidney - Countercurrent system - Passive hypothesis Medullary geometry - Pelvic urea - Mathematical model - Boundary value problem - Multiple shooting

\section{Introduction}

The countercurrent multiplier theory of the operation of the renal medulla (Kuhn and Ryffel, 1942) is by now generally accepted in physiology and medicine. The transport of sodium chloride from the ascending limb of Henle's loop through an epithelium impermeable for water creates a transepithelial difference in osmotic pressure (the "single effect"), which the anatomical arrangement of descending and ascending loop limbs permits to be multiplied by countercurrent flow. The thick part of the ascending limb was found to be capable of vigorous active salt transport (Burg and Green, 1973). However, physiological studies in vitro and in

* A portion of this study has been presented at the Oberwolfach Conference on Mathematical Biology, November 1981

** Part of the work was carried out while one of the authors (P. L.) was visiting at the State University of New York at Stony Brook. It was supported by the Science Committee of NATO via the DAAD 
vivo have failed to provide indisputable evidence for active transepithelial transport in either descending or thin ascending limbs (Kokko, 1970; Imai and Kokko, 1974).

Hence, Stephenson (1972) and independently Kokko and Rector (1972) proposed a passive mode. It ascribes a special role to urea for innermedullary osmotic concentration in the absence of active transport in the thin ascending limb of Henle. Furthermore, the latter authors presented a rather detailed scheme of solute concentrations and volume flow rates at various medullary locations, consistent with the requirement to conserve mass. However, their proposal is based on several a priori assumptions. As correctly pointed out by Jamison and Robertson (1979), there is no proof that their choices are those that would result from a mass balance using phenomenologic equations for transmembrane solute and water exchange processes, measured values of the membrane transport parameters, and measured solute concentrations and volume flow rates at the boundaries of the medulla. Indeed, the only appropriate means to examine a passive mode is to establish a mathematical model using experimentally measured membrane permeability coefficients and input values for flow and concentrations as previously done by Foster and Jacquez (1978) and Moore and Marsh (1980). Their results predict much lower concentration increases of renal solutes along the length of the inner medulla when compared to those measured by tissue slice analysis. The only mathematical model that could create such an increase was developed by Stephenson et al. $(1974,1976)$ and Mejia and Stephenson (1979). However, these calculations use an idealized parameter set suited for the study of basic capacities within a passive mode of osmotic concentration but it deviates from experimentally measured values.

The present work utilizes those experimentally measured parameters. Thermodynamic data on medullary nephron epithelia have been completely evaluated by in vitro techniques only in the rabbit kidney. The geometry of the countercurrent system is best known in the rat kidney. The medullary architecture of the tubular system, however, is quite similar in rat and rabbit (Kriz, 1981). The thermodynamic parameters of the rabbit, therefore, have been applied in this model to the geometry of the rat countercurrent system.

This study extends previous models by incorporating two new features (Lory et al., 1981). 1) A more realistic geometry of the collecting duct system as it converges towards the papilla. It is important to emphasize that this architecture is identical in rat and rabbit (Section 2.2). 2) Recent direct and indirect evidence for the importance of high pelvic urea concentrations and its possible (but not proven) reflux into the medullary interstitium (Bonventre et al., 1978, 1980; Schütz and Schnermann, 1972; Gertz et al., 1966; Schmidt-Nielsen et al., 1970, 1980; Oliver et al., 1982). High pelvic urea concentrations have been measured in rat and rabbit; in all mammalian species, the papilla is surrounded by the pelvic cavity (Kriz, 1981).

Our results show: 1) These features favour the generation of a steep solute concentration gradient from the outer-inner medullary junction to the tip of the papilla. For a set of parameters which is consistent with experimental data the results agree with the total tissue measurements. 2) The mathematical model study of the collecting duct system demonstrates that the measured non-equilibrium of urea between urine and papillary tissue water (Roch-Ramel et al., 1978; Gunther 
and Rabinowitz, 1980) does not contradict a relatively high urea permeability of the papillary collecting duct (Rocha and Kokko, 1974).

\section{The Mathematical Model}

According to both morphological and functional differences the mammalian kidney is divided into several zones: cortex, inner medulla (IM) and outer medulla $(O M)$ which is subdivided into outer stripe (OS) and inner stripe (IS).

Each kidney consists of thousands of basic functional units, the nephrons. Figure 2.1 shows two nephrons schematically. A filtrate of plasma enters the proximal tubule. It then flows along the various tubular segments of the nephron in the following order:

DLH descending limb of Henle's loop,

tALH thin part of ascending limb of Henle's loop,

TALH thick part of ascending limb of Henle's loop,

DCT distal convoluted tubule,

CNT connecting tubule,

$\mathrm{CD}$ collecting duct.

At the end of the CD the fluid empties into the renal pelvis.

The symbols and their units used in the mathematical model are listed in Table 2.1. The subscripts $i$ and $j$ correspond to the following:

$$
\begin{aligned}
& i=1 \mathrm{DLH}, \\
& i=2 \mathrm{ALH}, \\
& i=3 \mathrm{DCT} / \mathrm{CNT}, \\
& i=4 \mathrm{CD} \\
& i=5 \text { pelvis, } \\
& i=6 \mathrm{CC} \text { (central core), }
\end{aligned}
$$

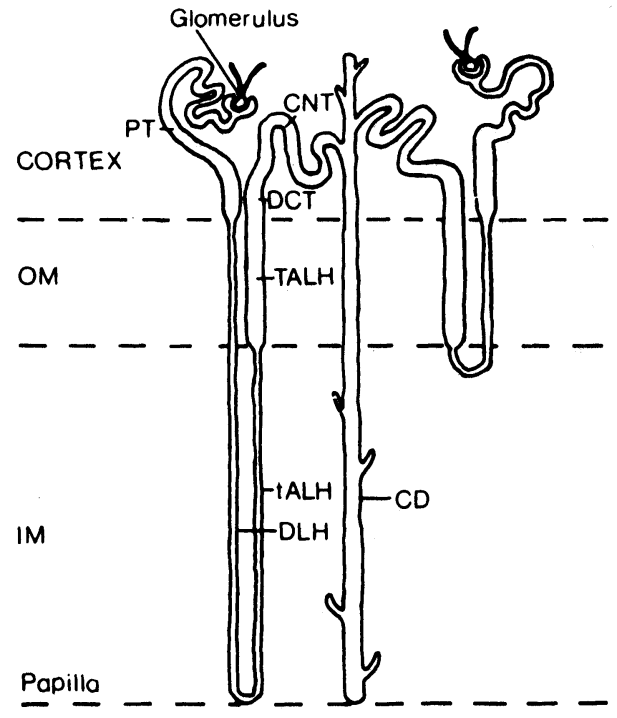

Fig. 2.1. Schematic presentation of two nephrons (modified from Fourman and Moffat, 1971) 
Table 2.1. Glossary of Symbols

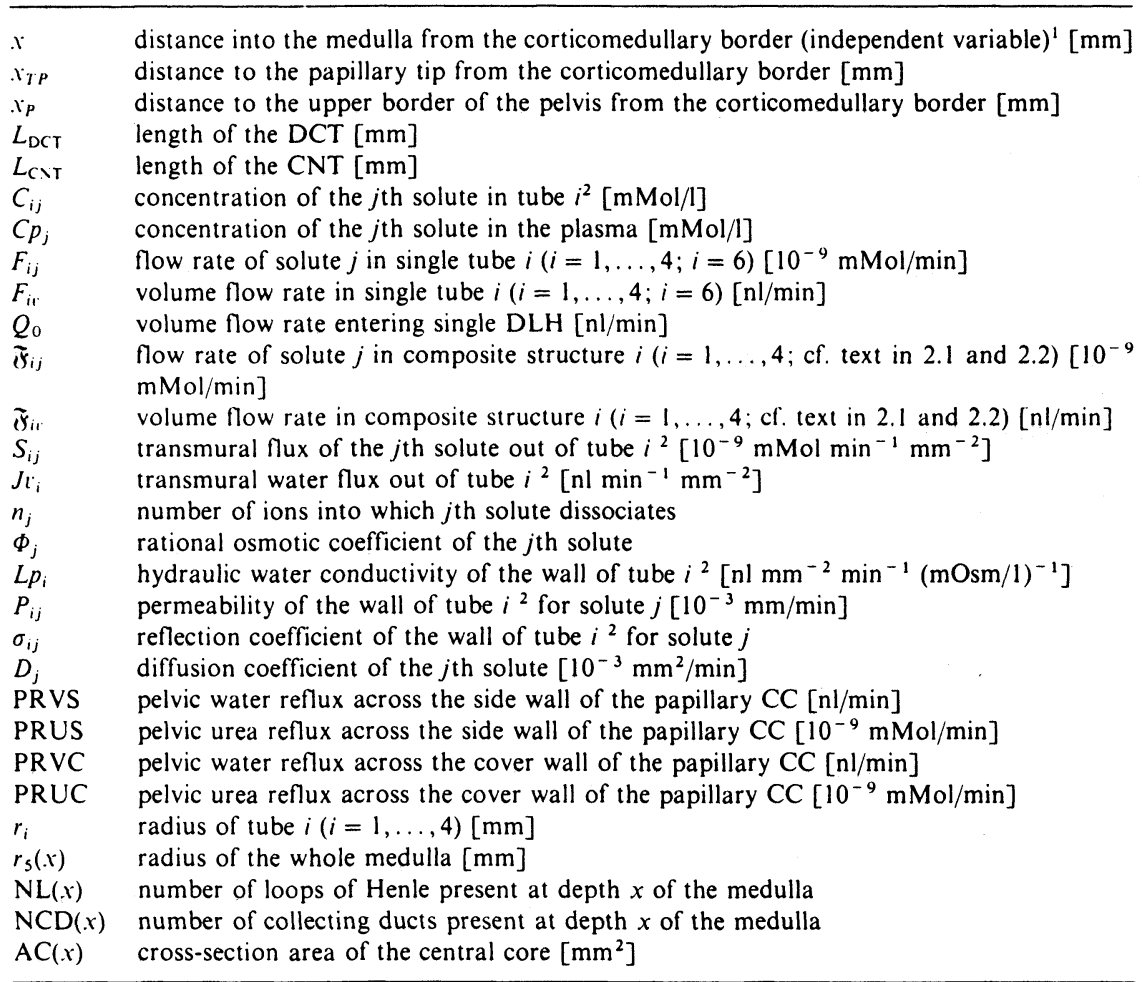

1 For $i=3(\mathrm{DCT} / \mathrm{CNT}) x$ is measured along the tube so that $x=0$ and $x=L_{\mathrm{DCT}}+L_{\mathrm{CNT}}$ correspond to its junctions with tube 2 and tube 4 , respectively

${ }^{2}$ For $i=5$ : pelvis

Central Core: The vasa recta (VR) form the vascular system associated with the nephrons. They are highly permeable both to salt and urea. Therefore, as suggested by Stephenson (1972), they can be functionally merged with the interstitium into a single fluid-filled space called central core. The consequences of this basic idea for mathematical modelling are described in detail by Jacquez et al. (1976). For $i=1,2,4,5$ the transmural fluxes are given by

$$
\begin{aligned}
J v_{i} & =L p_{i} \sum_{j=1}^{2} n_{j} \Phi_{j} \sigma_{i j}\left(C_{6 j}-C_{i j}\right), \\
S_{i j} & =P_{i j}\left(C_{i j}-C_{6 j}\right)+\left(1-\sigma_{i j}\right) J v_{i} \overline{C_{i j}}+T_{i j}, \quad j=1,2,
\end{aligned}
$$

where $\overline{C_{i j}}:=\left(C_{i j}+C_{6 j}\right) / 2$. The active transport $T_{i j}$ is assumed to obey MichaelisMenten kinetics, namely

$$
T_{i j}=\frac{V m_{i j} C_{i j}}{K m_{i j}+C_{i j}}
$$


where $V m_{i j}$ is the maximum rate of transport and $K m_{i j}$ is the Michaelis constant. In the model, salt only is transported actively and this transport occurs in TALH and DCT/CNT only. Hence, the model is based on the passive hypotheses of inner medullary countercurrent multiplication (Kokko and Rector, 1972, Stephenson, 1972).

Although there is active $\mathrm{NaCl}$ reabsorption in the $\mathrm{CD}$ (Laurence and Marsh, 1971), much of it is involved in cation exchange processes, so that its overall effect in raising inner medullary osmolarity may be ignored. Moreover, the magnitude of $\mathrm{CD}$ salt reabsorption is much lower than that occurring in the loop of Henle, and its effect on axial salt gradients may be neglected. Hence the CD is assumed to be impermeable to salt. This assumption also allows the effect of other nonreabsorbable solutes on $C D$ water reabsorption to be included as discussed in more detail by Bonventre and Lechene (1980), Moore and Marsh (1980), Kokko and Rector (1972). Also, this assumption is consistent with experimental observations by Frindt and Burg (1972), Ullrich et al. (1958) and Hilger et al. (1958).

During passage through the DCT/CNT, the fluid interacts with the cortical interstitium, where the solute concentrations are assumed to be the same as in arterial plasma. Hence in this region:

$$
\begin{aligned}
& J v_{3}=L p_{3} \sum_{j=1}^{2} n_{j} \Phi_{j} \sigma_{3 j}\left(C p_{j}-C_{3 j}\right), \\
& S_{3 j}=P_{3 j}\left(C_{3 j}-C p_{j}\right)+\left(1-\sigma_{3 j}\right) J v_{3} \overline{C_{3 j}}+T_{3 j}, \quad j=1,2 .
\end{aligned}
$$

For the reasons outlined by Moore and Marsh (1980) it was assumed that in the tubules axial movement of solute is by convection only:

$$
F_{i j}=F_{i v} C_{i j}, \quad i=1, \ldots, 4, \quad j=1,2 \quad\left(\mathfrak{F}_{i j}=\mathfrak{F}_{i v} C_{i j} \text { respectively }\right) .
$$

However, in the central core, solute movement along the corticomedullary axis can occur by both diffusion and convection:

$$
F_{6 j}=F_{6 v} C_{6 j}-D_{j} \cdot \mathrm{AC}(x) d C_{6 j} / d x, \quad j=1,2 .
$$

\subsection{Loop Anatomy}

The loops of Henle turn at different levels of the renal medulla. Figure 2.2 shows the function $\mathrm{NL}(x)$, which is based on the morphological findings of Kriz (1967), Oliver (1968), and Sperber (1944). Seventy percent of the loops turn in the inner third of the inner stripe, whereas the remaining $30 \%$ turn in the inner medulla.

Because of the large number of nephrons it is impossible to model each of the loops separately.

This would require thousands of (basically similar) differential equations. So, following a previous suggestion of Moore and Marsh (1980), a composite loop structure was used in the model. For purposes of demonstration only, Fig. 2.3 shows a composite loop structure representing a group of 4 single nephrons of different length. Each shunt pathway reflects the effect of a single loop turning. At each level, the circumference of the composite structure equals the total circumference of the represented loops, thus yielding the same effective surface area per unit 


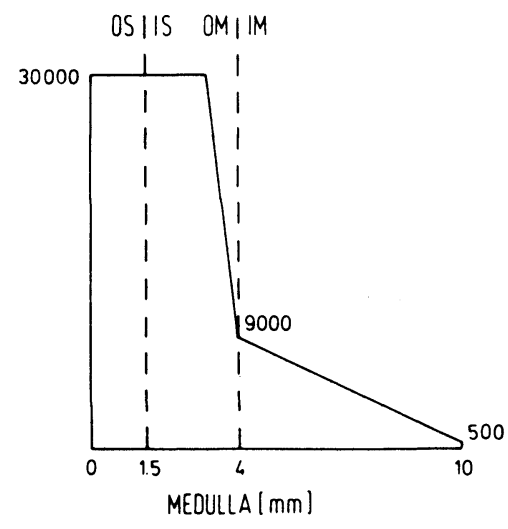

Fig. 2.2. Distribution of loops of Henle within the renal medulla
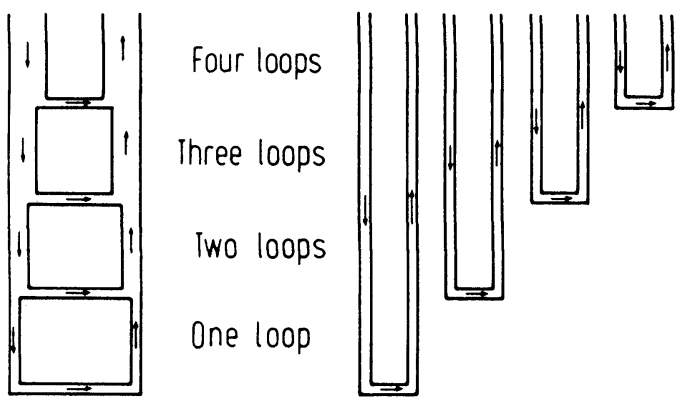

Fig. 2.3. Composite loop structure which represents a group of single nephrons of different length. A shunt pathway represents a single loop turning, and arrows indicate the direction of flow

length in both structures. The flows in the composite loop structure represent the sum of flows in the single loops at the corresponding level, and the concentration in the fluid within the composite structure reflects the mixture of the fluids in the single tubules.

The differential equations describing local mass balance for the composite DLH and ALH structures may be established analogously to the single tube case (see e.g. Stephenson, 1973). Here the limiting process is justified by the high number of shunts.

Composite DLH (' denotes $d / d x)$ :

$$
\begin{aligned}
& d \mathbb{F}_{1} / d x=-2 \pi r_{1} \cdot \mathrm{NL}(x) \cdot J v_{1}+\mathrm{NL}^{\prime}(x) \cdot \mathfrak{F}_{1 v} / \mathrm{NL}(x), \\
& d \mathfrak{F}_{1 j} / d x=-2 \pi r_{1} \cdot \mathrm{NL}(x) \cdot S_{1 j}+\mathrm{NL}^{\prime}(x) \cdot \mathfrak{F}_{1 j} / \mathrm{NL}(x), \quad j=1,2, \\
& \tilde{F}_{1 r}(0)=Q_{0} \cdot \mathrm{NL}(0) \text {, } \\
& \varpi_{11}(0)=Q_{0} \cdot C p_{1} \cdot \mathrm{NL}(0), \quad \oiint_{12}(0)=Q_{0} \cdot 2 C p_{2} \cdot \mathrm{NL}(0) .
\end{aligned}
$$

Composite $A L H$ :

$$
\begin{aligned}
& d \mathfrak{\mho}_{2 v} / d x=-2 \pi r_{2} \cdot \mathrm{NL}(x) \cdot J v_{2}-\mathrm{NL}^{\prime}(x) \cdot \mathfrak{F}_{1 v} / \mathrm{NL}(x), \\
& d \mathfrak{F}_{2 j} / d x=-2 \pi r_{2} \cdot \mathrm{NL}(x) \cdot S_{2 j}-\mathrm{NL}^{\prime}(x) \cdot \mathfrak{F}_{1 j} / \mathrm{NL}(x), \quad j=1,2, \\
& \mathfrak{\mho}_{2 r}\left(x_{T P}\right)=-\mathfrak{F}_{1 v}\left(x_{T P}\right), \\
& \tilde{\mho}_{2 j}\left(x_{T P}\right)=-\mathfrak{\mho}_{1 j}\left(x_{T P}\right), \quad j=1,2 .
\end{aligned}
$$


In the differential equations the first term on the right hand side is the transmural flux contribution and the second is the contribution of the shunt flows.

These equations may be simplified by the following transformations:

$$
\begin{aligned}
& \mathfrak{F}_{1 v}(x)=F_{1 v}(x) \cdot \mathrm{NL}(x), \\
& \mathfrak{F}_{1 j}(x)=F_{1 j}(x) \cdot \mathrm{NL}(x), \quad j=1,2,
\end{aligned}
$$

yielding the following differential equations:

$$
\begin{aligned}
d F_{1 v} / d x & =-2 \pi r_{1} J v_{1}, \\
d F_{1 j} / d x & =-2 \pi r_{1} S_{1 j}, \quad j=1,2, \\
d F_{2 v} / d x & =-2 \pi r_{2} \cdot \mathrm{NL}(x) \cdot J v_{2}-\mathrm{NL}^{\prime}(x) \cdot F_{1 v}, \\
d F_{2 j} / d x & =-2 \pi r_{2} \cdot \mathrm{NL}(x) \cdot S_{2 j}-\mathrm{NL}^{\prime}(x) \cdot F_{1 j}, \quad j=1,2 .
\end{aligned}
$$

In the DCT/CNT, the number of tubes is constantly $\mathrm{NL}(0)$. Thus, the differential equations for the according composite structure are

$$
\begin{aligned}
& d \mathfrak{F}_{3 v} / d x=-2 \pi r_{3} \cdot \mathrm{NL}(0) \cdot J v_{3}, \\
& d \mathfrak{F}_{3 j} / d x=-2 \pi r_{3} \cdot \mathrm{NL}(0) \cdot S_{3 j}, \quad j=1,2 .
\end{aligned}
$$

\subsection{Collecting Duct Architecture}

The geometry of the collecting duct system in outer and inner medulla is identical in rat and rabbit (Kriz, 1981). According to Kriz (1967), Kaissling and Kriz (1979) six nephrons drain into one cortical collecting duct. Hence, for the outer medulla: $\operatorname{NCD}(x)=\mathrm{NL}(0) / 6$. In the inner medulla, the collecting ducts merge in a dichotomous manner resulting in a tree composed of about $2^{9} \mathrm{CD}$ (Kaissling and Kriz, 1979, and Kainer, 1975).

Thus, the total circumference of all CD decreases exponentially from the outerinner-medullary junction to the tip of the papilla. This fact is reflected in the composite $\mathrm{CD}$ structure:

$$
\begin{aligned}
& d \mathfrak{F}_{4 v} / d x=-2 \pi r_{4} \cdot \operatorname{NCD}(x) \cdot J v_{4}, \\
& d \mathfrak{F}_{4 j} / d x=-2 \pi r_{4} \cdot \operatorname{NCD}(x) \cdot S_{4 j}, \quad j=1,2,
\end{aligned}
$$

with

$$
\mathrm{NCD}(x)=\left\{\begin{array}{l}
\mathrm{NL}(0) / 6 \text { in OM } \\
\text { exponentially decreasing in IM (for details see Section 3) }
\end{array}\right.
$$

\subsection{Pelvic Reflux}

Recent studies have revealed that the epithelium covering the papilla is permeable to urea and possibly to water (Bonventre et al., 1978, Schmidt-Nielsen et al., 1980). Moreover, it has been shown that the composition of the fluid bathing the papilla is an important determinant of inner medullary solute concentration (Schütz and Schnermann, 1972, Bonventre et al., 1980, Gertz et al., 1966). 


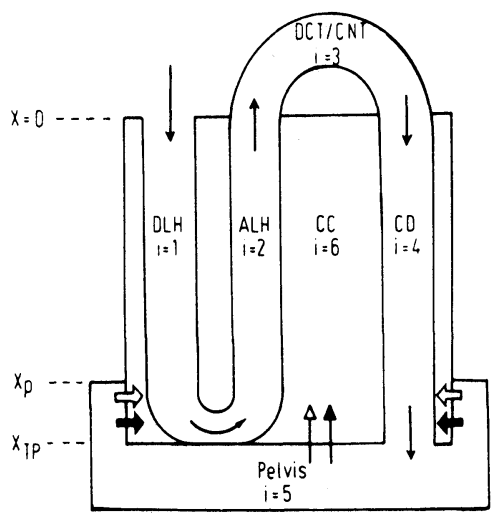

Fig. 2.4. Schematic presentation of the central core model (omitting medullary architecture) with pelvic reflux across the side wall of the papillary CC (PR VS: $\Rightarrow$, PRUS: $\rightarrow$ ) and across its cover wall (PRVC: $\rightarrow$, PRUC: $\rightarrow$ )

Hence, the pelvis is incorporated in the model as a single, well-mixed compartment surrounding the papilla as indicated in Fig. 2.4. Consequently, the concentrations of salt $C_{51}$ and of urea $C_{52}$ in the pelvis are assumed to be independent of $x$.

The total amounts of pelvic reflux across the side wall of the papillary CC of water and of urea are determined by:

$$
\begin{aligned}
& \text { PRVS }=\int_{x_{P}}^{x_{T P}} 2 \pi r_{5}(x) J v_{5}(x) d x, \\
& \text { PRUS }=\int_{x_{P}}^{x_{T P}} 2 \pi r_{5}(x) S_{52}(x) d x .
\end{aligned}
$$

Similarly, across the cover wall:

$$
\begin{aligned}
& \mathrm{PRVC}=\mathrm{AC}\left(x_{T P}\right) \cdot L p_{5} \sum_{j=1}^{2} n_{j} \Phi_{j}\left(C_{6 j}\left(x_{T P}\right)-C_{5 j}\right), \\
& \mathrm{PRUC}=\mathrm{AC}\left(x_{T P}\right) \cdot P_{52}\left(C_{52}-C_{62}\left(x_{T P}\right)\right) .
\end{aligned}
$$

The differential equations for the tubes and the pelvis are coupled by the differential equations for the central core flows which are derived from the requirement of mass balance:

$$
\begin{aligned}
& d F_{6 v} / d x=-\sum_{\substack{i=1 \\
i \neq 3}}^{4} d \mathfrak{F}_{i v} / d x+2 \pi r_{5}(x) J v_{5}, \\
& d F_{6 j} / d x=-\sum_{\substack{i=1 \\
i \neq 3}}^{4} d \mathfrak{F}_{i j} / d x+2 \pi r_{5}(x) S_{5 j}, \quad j=1,2,
\end{aligned}
$$

where $S_{51}=0$. For the numerical calculation (see Section 4), (15) and (16) have been transformed to differential equations:

$$
\begin{array}{ll}
\operatorname{prvs}^{\prime}(x)=2 \pi r_{5}(x) \cdot J v_{5}(x), & \operatorname{prvs}\left(x_{P}\right)=0, \\
\operatorname{prus}^{\prime}(x)=2 \pi r_{5}(x) \cdot S_{5_{2}}(x), & \operatorname{prus}\left(x_{P}\right)=0 .
\end{array}
$$

As a consequence,

$$
\operatorname{prvs}\left(x_{T P}\right)=\operatorname{PRVS}, \quad \operatorname{prus}\left(x_{T P}\right)=\operatorname{PRUS} .
$$


Altogether, (6) - (14) and $\left(15^{\prime}\right),\left(16^{\prime}\right),(17),(18)$ define a system of 19 simultaneous nonlinear differential equations of first order for $F_{1 v}, F_{11}, F_{12}, \mathbb{F}_{2 v}, \mathbb{F}_{21}, \mathbb{F}_{22}, \mathbb{F}_{3 v}$, $\tilde{\mho}_{31}, \mathbb{\mho}_{32}, \mathbb{F}_{4 l}, \mathbb{F}_{41}, \mathbb{F}_{42}$, prvs, prus, $F_{6 v}, F_{61}, F_{62}, C_{61}, C_{62}$. Additionally to these unknown functions the two parameters $C_{51}$ and $C_{52}$ (pelvic concentrations) are to be determined (eigenvalue problem). The transmural fluxes occurring in the right hand side are defined by Eqs. (1) - (5).

The corresponding 21 boundary conditions are given in $\left(15^{\prime}\right),\left(16^{\prime}\right)$ and in the following Eqs. (19) - (26).

The boundary conditions for the tubes are

$$
\begin{gathered}
F_{1 !}(0)=Q_{0}, \quad F_{11}(0)=Q_{0} \cdot C p_{1}, \quad F_{12}(0)=Q_{0} \cdot 2 C p_{2}, \\
\mathfrak{F}_{2 v}\left(x_{T P}\right)=-F_{1 v}\left(x_{T P}\right) \cdot \mathrm{NL}\left(x_{T P}\right), \\
\mathfrak{F}_{2 j}\left(x_{T P}\right)=-F_{1 j}\left(x_{T P}\right) \cdot \mathrm{NL}\left(x_{T P}\right), \quad j=1,2, \\
\mathfrak{F}_{3 v}(0)=-\mathfrak{F}_{2 v}(0), \quad \mathfrak{F}_{3 j}(0)=-\mathfrak{F}_{2 j}(0), \quad j=1,2, \\
\mathfrak{\mho}_{4 v}(0)=\mathfrak{F}_{3 v}\left(L_{\mathrm{DCT}}+L_{\mathrm{CNT}}\right), \quad \mathbb{F}_{4 j}(0)=\mathfrak{F}_{3 j}\left(L_{\mathrm{DCT}}+L_{\mathrm{CNT}}\right), \quad j=1,2 .
\end{gathered}
$$

The boundary conditions for the central core are

$$
\begin{gathered}
C_{6 j}(0)=C p_{j}, \quad j=1,2, \\
F_{6 v}\left(x_{T P}\right)=- \text { PRVC }, \quad F_{61}\left(x_{T P}\right)=0, \quad F_{62}\left(x_{T P}\right)=- \text { PRUC. }
\end{gathered}
$$

The boundary conditions for the pelvis result from the requirement of mass balance:

$$
\begin{aligned}
& \left(\mathfrak{F}_{4 v}\left(x_{T P}\right)-\mathrm{PRVS}-\mathrm{PRVC}\right) C_{51}=\mathfrak{F}_{41}\left(x_{T P}\right), \\
& \left(\mathfrak{F}_{4 v}\left(x_{T P}\right)-\mathrm{PRVS}-\mathrm{PRVC}\right) C_{52}=\mathfrak{F}_{42}\left(x_{T P}\right)-\text { PRUS - PRUC. }
\end{aligned}
$$

\section{Model Parameters for the Base Case}

The following values for the thickness of medullary zones were incorporated into the model (Sperber, 1944; Kriz, 1967; Moore and Marsh, 1980): OM, 4 mm; IM, 6 $\mathrm{mm}$; OS, $1.5 \mathrm{~mm}$; IS, $2.5 \mathrm{~mm}$. $L_{\mathrm{DCT}}=1 \mathrm{~mm}$ and $L_{\mathrm{CNT}}=2.5 \mathrm{~mm}$ (Kaissling, 1978; Kaissling and Kriz, 1979). The radii of the individual tubes are: DLH, $8 \mu \mathrm{m}$; ALH/DCT, $10 \mu \mathrm{m}$; OMCD, $12 \mu \mathrm{m}$; DVR, $11 \mu \mathrm{m}$; AVR, $20 \mu \mathrm{m}$ (Moore and Marsh, 1980). In CNT the radius varies linearly from 10 to $8 \mu \mathrm{m}$. This is consistent with Ullrich et al. (1964) and Capek et al. (1966). The radius of IMCD is explained below.

The function $\mathrm{NL}(x)$ was already defined in Section 2. On the average, six nephrons drain into one CD (Kriz, 1967; Kaissling and Kriz, 1979). Hence, in the outer medulla $\operatorname{NCD}(x)=5000$. In the inner medulla, Kaissling and Kriz (1979) observed that the CD merge at about 9 dichotomous junctions. A thorough description of this CD-system summarizing the experimental results of Kriz was presented by Kainer (1975). To incorporate these features of the CD, an exponential decrease of the total circumference of the CD-system in the inner medulla was used:

$$
\mathrm{NCD}(x)=5000 \exp (-0.933(x-4.0))
$$


P. Lory et al.

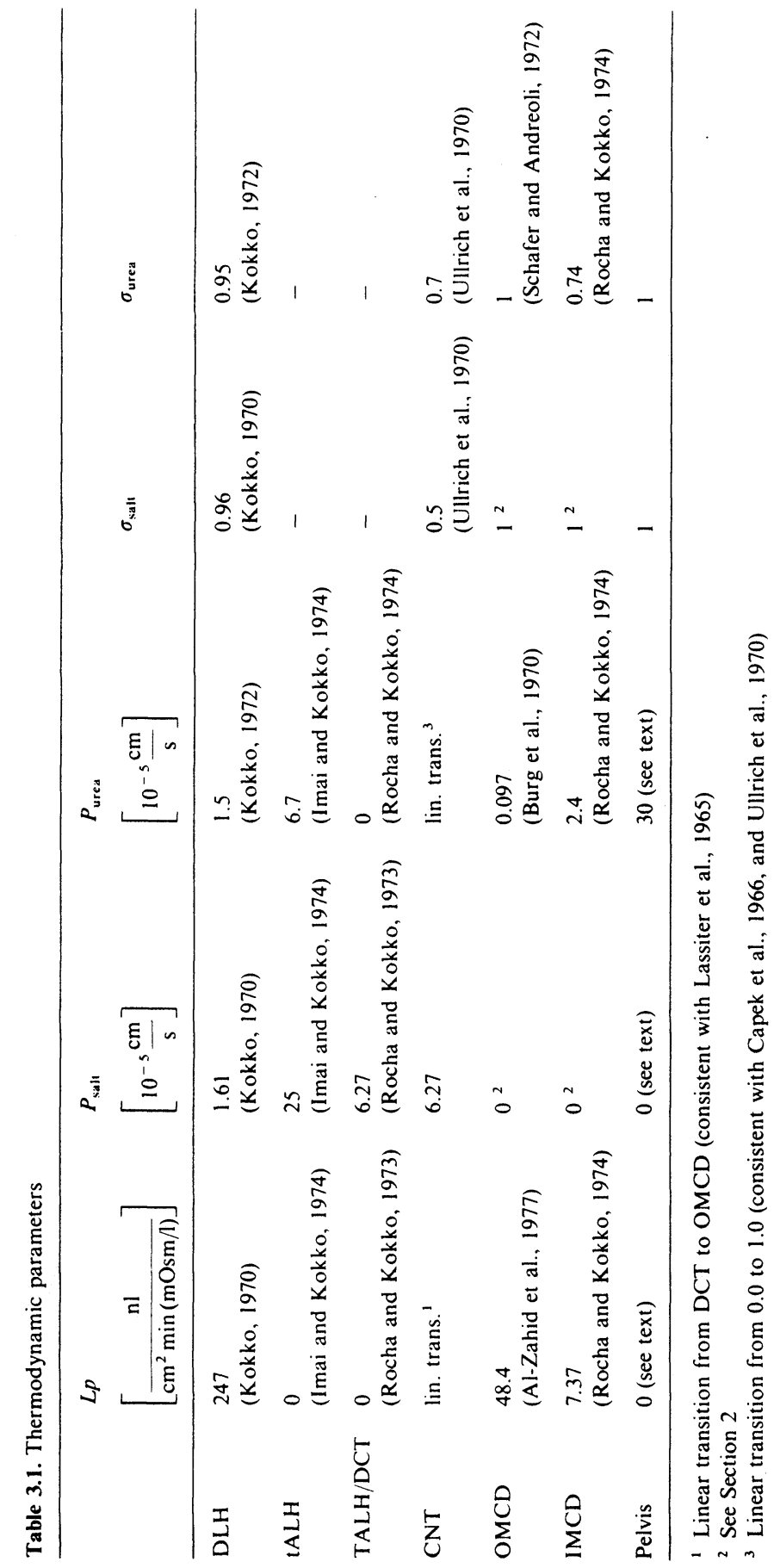


This function not only reflects the decrease in the number of $C D$, but also the approximate doubling of the radius of a single $C D$ from the outer-inner medullary junction to the papillary tip.

The interstitial cross-sectional area $\mathrm{AI}(x)$ (including tubular cell volume) was estimated to be $40 \%$ of the total tubular luminal cross-sectional area (Marsh et al., 1967, and Knepper et al., 1977). According to Kriz (1967), the relation $\operatorname{NVR}(x)=1.3 \cdot \mathrm{NL}(x)$ was used for the number of vasa recta. The cross-sectional area of the central core $\mathrm{AC}(x)$ is defined as the sum of $\mathrm{AI}(x)$ and the total tubular cross-sectional area of the vasa recta.

The thermodynamic parameters are presented in Table 3.1. Values are those measured directly in isolated perfused tubules. This in vitro perfusion technique of single tubule segments provides data on thermodynamic parameters of those tubular segments which cannot be obtained by any other technique, i.e., on DLH, tALH, TALH and CD.

For the CD parameters, a linear transition zone from OMCD to IMCD was assumed in $4.0 \leqslant x \leqslant 7.0$. This assumption was not made to facilitate the numerical computation. Rather, this gradual transition seems reasonable as some parameters differ substantially between OMCD and IMCD. This transition zone does not contradict the measurements of Rocha and Kokko (1974) as these data were obtained in the papillary CD. However, between the tALH and the TALH a discontinuous change of the parameters was incorporated in the model. The arguments for the abrupt transition have been presented previously (Lory, 1980).

A comment on the outermedullary $\mathrm{CD}$ parameters seems in place. The only available measurements for the water conductivity in the OMCD (Horster and Zink, 1982) were obtained at a temperature of $25^{\circ} \mathrm{C}$. Therefore, the value of $\mathrm{Al}$ Zahid et al. (1977) at $37^{\circ} \mathrm{C}$ was used in the model, although this was obtained in the cortical CD. Consequently, cortical CD measurements (Burg et al., 1970) have been used for the urea permeability as well. Their very low value $(0.097)$ is backed by the general assumption of almost impermeability of the OMCD for urea (Bonventre and Lechene, 1980). Nevertheless, a simulation run using the higher OMCD urea permeability (0.34) of Rocha and Kokko (1974) will also be presented.

For the permeability of the wall separating the pelvis and the papillary interstitial space direct measurements are not available. However, morphologic studies of Bonventre et al. (1978) suggest a rather high urea permeability. This assumption and that of a very low water conductivity are supported by the studies of Bonventre et al. (1980). In Section 5, the effects of variations of pelvic water and urea permeabilities will be studied. In all simulations, impermeability to salt is assumed, as suggested by experimental findings (Gertz et al., 1966; SchmidtNielsen et al., 1970). The active transport parameters $\mathrm{Vm}$ and $\mathrm{Km}$ for the TALH/DCT and the CNT were estimated by comparing the end ALH and end CNT concentrations and water flows with measured values. In all simulations presented here, $V m=22 \cdot 10^{-6} \mathrm{mMol} \mathrm{cm}{ }^{-2} \mathrm{sec}^{-1}$ and $K m=50 \mathrm{mMol} / 1$ were used.

The volume flow rate into a single DLH was assumed to be $10 \mathrm{nl} / \mathrm{min}$. The plasma concentrations of salt and urea were assumed to be 140 and $9 \mathrm{mMol} / 1$ respectively. The rational osmotic coefficients are $\Phi_{1}=0.91$ and $\Phi_{2}=1.0$. 


\section{Numerical Solutions and Results for the Base Case}

The boundary value problem (1) - (26) was solved numerically by multiple shooting (Bulirsch, 1971; Stoer and Bulirsch, 1980). This method has been proven to yield precise and reliable results. Its applicability to kidney models has been demonstrated (Lory, 1980). The computations were performed on the CDC Cyber 175 (48-bit mantissa) of the Leibniz-Rechenzentrum der Bayerischen Akademie der
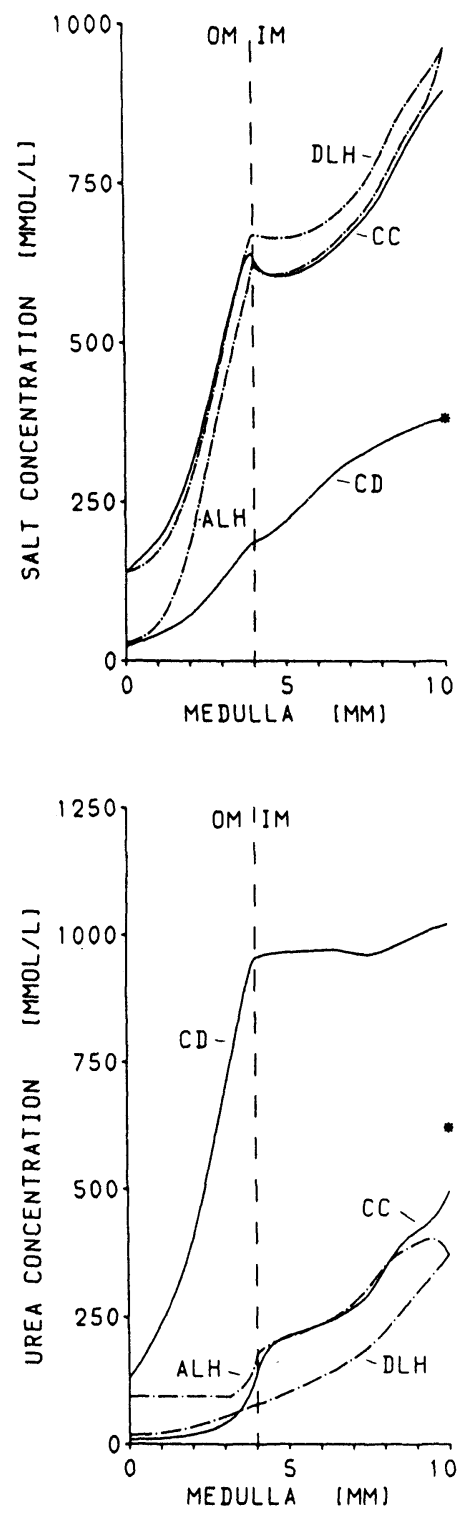

Fig. 4.1. Computed salt concentrations for the base case in $\mathrm{DLH}, \mathrm{ALH}(-\cdots)$, in $\mathrm{CD}, \mathrm{CC}(-)$ and in pelvis $(*)$

Fig. 4.2. Computed urea concentrations for the base case in DLH, ALH (- - - ) , in CD, CC (-) and in pelvis (*) 
Table 4.1. TF/P ratios for inulin (base case)

\begin{tabular}{lrrr}
\hline & DLH & ALH & \multicolumn{1}{c}{ CD } \\
\hline$x=0$ & 3.00 & 14.53 & 29.88 \\
$x=4$ & 15.05 & 18.22 & 239.61 \\
$x=10$ & 25.28 & 25.28 & 486.07 \\
\hline
\end{tabular}

Wissenschaften. Here, a code was used which solves the linear equations for the Newton-corrections in a direct manner (Oberle, 1982). The modified Newtoniteration (Deuflhard, 1975) was terminated when the relative precision of the solution was less than $1 \cdot 10^{-5}$. The initial value subproblems (see Stoer and Bulirsch, 1980) were solved by RKF 7, a Runge-Kutta-Fehlberg method of seventh order (Fehlberg, 1969) with an automatic control of the integration stepsizes according to the prescribed tolerance (here $1 \cdot 10^{-8}$ ). An important check for the results is the overall conservation of mass for the entire medulla. Mass inflow agreed with mass outflow to a relative accuracy of at least $2 \cdot 10^{-9}$ for both water and the solutes.

The computed concentration profiles for salt and urea in the medullary structures are shown in Figs. 4.1 and 4.2. Characteristic values of tubular fluid to plasma ratios $(\mathrm{TF} / \mathrm{P})$ for inulin describing water flow are given in Table 4.1. For the physiological interpretation of these data the reader should have in mind that they describe the fluid in the composite loop structure (see Section 2) and not in a single tubule (except DLH).

The thermodynamic parameters used in the model were measured in the rabbit, the animal to which the in vitro technique can be applied (see Section 3). On the other hand, micropuncture measurements in the rabbit kidney are extremely difficult and only a few are available (Jamison and Robertson, 1979). Therefore, the computed results will be compared mainly with concentration measurements in tissue slices. Let the weighting factors $w_{i}(x)$ describe the ratio of the cross-sectional area of the $i$ th region to the total cross-sectional area of the medulla at depth $x$. Then the slice concentrations $\mathrm{SC}_{1}(x)$ (salt) and $\mathrm{SC}_{2}(x)$ (urea) predicted by the model are given by

$$
\mathrm{SC}_{j}(x)=\sum_{\substack{i=1 \\ i \neq 3 \\ i \neq 5}}^{6} w_{i}(x) C_{i j}(x), \quad j=1,2
$$

Figure 4.3 compares $\mathrm{SC}_{2}(x)$ with measurements in the rabbit (Gunther and Rabinowitz, 1980) and in the rat (Hai and Thomas, 1969) and shows good agreement. An analogous comparison for salt with the experimental findings of the same authors (Fig. 4.4) is less satisfactory. This may be at least partly be attributed to the fact that the intracellular concentration of sodium (but not urea) is probably low relative to the intraluminal and the interstitial compartment. Thus, measurements of this ion in a homogenate of the renal medulla will significantly underestimate the concentration actually present in the interstitial and intratubular space. In any case, electron microprobe measurements by Koepsell et al. 

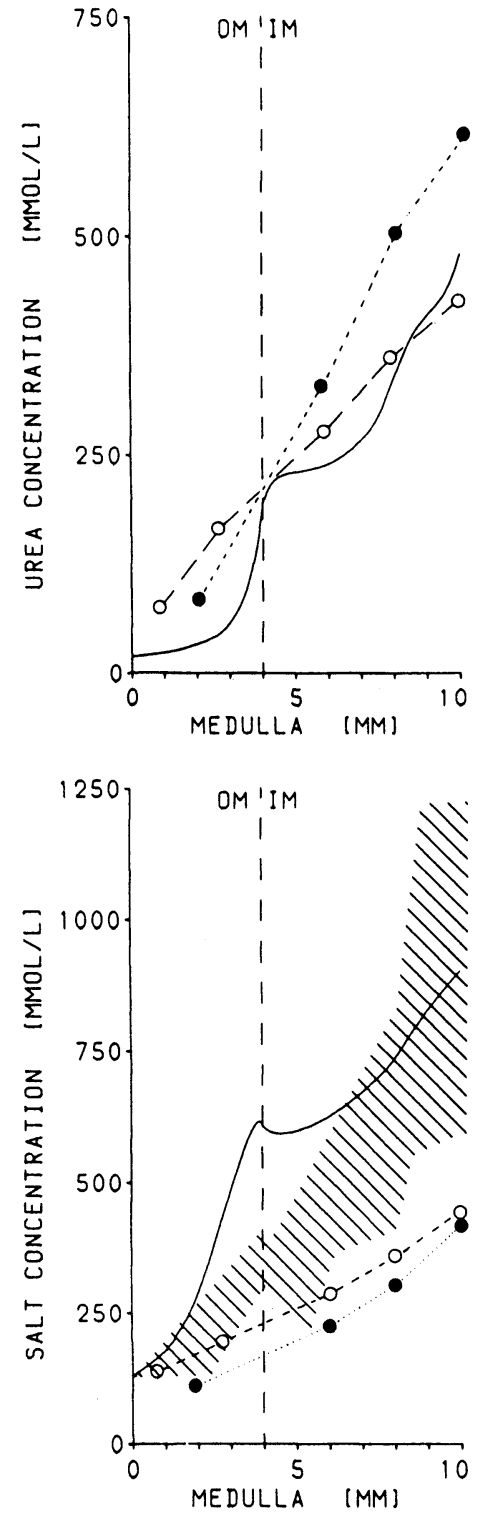

Fig. 4.3. Comparison of the computed total tissue concentration for urea $\mathrm{SC}_{2}(x)$ with slice concentration measurements of Gunther and Rabinowitz (1980) (O), and Hai and Thomas (1969) (•)

Fig. 4.4. Comparison of the computed total tissue concentration for salt $\mathrm{SC}_{1}(x)$ with slice concentration measurements of Gunther and Rabinowitz (1980) (O), Hai and Thomas (1969) (๑), and Koepsell et al. (1974) (hatched area)

(1974) have revealed a large increase of salt concentration. These measurements are in acceptable agreement with $\mathrm{SC}_{1}(x)$.

$\mathrm{SC}_{1}(x)$ and $\mathrm{SC}_{2}(x)$ increase progressively in both zones of the medulla. Fiftysix percent $(1046 \mathrm{mOsm} / \mathrm{l})$ of the rise in total osmolarity occur in the outer medulla and fortyfour percent $(820 \mathrm{mOsm} / \mathrm{l})$ in the inner zone. Urea accounts for about $23 \%$ of total tissue osmolarity in the papilla which is in close agreement with the data $(19 \%)$ of Roch-Ramel et al. (1978). Using measured values for the parameters, 
previous matnematical models of the passive mode could yield only a modest increase in osmolarity along the length of the inner medulla (Moore and Marsh, 1980) or even no increase at all (Foster and Jacquez, 1978). Reasons for this behaviour will be discussed in Section 5. However, it should be mentioned that the results of Moore and Marsh (1980) take into account an incomplete osmotic equilibration between ascerrding and descending vasa recta.

\subsection{Loop of Henle}

The model predicts osmotic equilibration of the DLH-fluid with the surrounding interstitium mainly by extraction of water. This prediction is consistent with the experimental findings of Kokko (1970). The decrease of flow rate in the DLH occurs principally in the outer medulla, whereas urea entry takes place along the inner medulla. These results agree with Pennell et al. (1975). At the papillary tip, DLH urea concentration is less than that in CC and it far exceeds the corresponding value in the scheme of Kokko and Rector (1972). These predictions are in agreement with Pennell et al. (1975) and Marsh (1970).

The scheme of Kokko and Rector (1972) assumes that urea diffuses into the tALH throughout the entire inner medulla. This is not supported by the results of the present model. Indeed, as fluid flows up the first portion of the tALH, the model predicts a rise in urea concentration due to urea entry. This feature was observed in vivo by Marsh (1970). However, in other parts of the tALH urea concentration in the composite tALH is almost in equilibrium with the urea concentration in CC, and both urea entry and exit occur depending on the relative location in the medulla.

Concerning the behaviour of salt in the loop of Henle the results of this model support the assumptions of Kokko and Rector (1972): At the papilla the computed salt concentration in the DLH fluid exceeds that in the adjacent tALH and CC (Marsh, 1970; Johnston et al., 1977) and salt leaves tALH in a strictly passive mode (Imai and Kokko, 1974).

The computed TF/P ratio for inulin at the bend of Henle's loop exceeds the experimentally measured value (Marsh, 1970). However, these measurements were made in an exposed papilla after resecting the pelvis. Hence, they are not fully applicable to the present model.

\subsection{DCT/CNT and Collecting Duct}

Active salt reabsorption by the TALH in this model produces hyposmotic fluid in numerically good agreement with data from micropuncture studies (Gottschalk and Mylle, 1959). During its passage through the DCT and the CNT, urea becomes the dominant solute. The model predicts that in the early DCT $72 \%$ and in the late CNT $49 \%$ of the filtered urea load is present in the tubule. These ratios agree well with corresponding values given by Roch-Ramel et al. (1978) for superficial nephrons.

In the OMCD water extraction raises the concentration of both salt and urea considerably. This high urea concentration at the outer-inner medullary junction is maintained against relatively low urea concentration in the surrounding CC 
although the highest measured urea permeability (Rocha and Kokko, 1974) was used in the model. More than one half $(53 \%)$ of the IMCD urea load reaches the pelvis. The exponential decrease of the effective surface area per unit length of the CD-tree is decisive for this behaviour. For details see the simulation studies in Section 5. Recently, Roch-Ramel et al. (1978) and Gunther and Rabinowitz (1980) have reported non-equilibrium of urea between urine and papillary tissue water of rabbits. Because of these experimental findings they suggested a low urea permeability of the collecting duct epithelium in the inner medulla, a conclusion which is in conflict with measurements of Rocha and Kokko (1974). The present model shows that the observations by Roch-Ramel et al. (1978) and Gunther and Rabinowitz (1980) do not contradict the high urea permeability reported by Rocha and Kokko (1974).

\subsection{Central Core}

Salt concentration in the CC (Fig. 4.1) rises from 140 to $635 \mathrm{mMol} / \mathrm{l}$ in the outer medulla and further to 894 in the papilla. Recent direct measurements of interstitial elemental concentrations by Bulger et al. (1981) show the following values (wet weight, $\mathrm{mMol} / \mathrm{kg}$ ) at the papillary tip: $\mathrm{Na} 590 \pm 119 ; \mathrm{Cl} 445 \pm 115 ; \mathrm{K} 42 \pm 8$. These data indicate that the computed value is within the range of the measured data. It should be mentioned that the data of Bulger et al. (1981) have been confirmed, in general, by Beck et al. (1981) who report some $450 \mathrm{~m} \mathrm{Mol} / \mathrm{l}$ of salt at the papillary level.

\subsection{Pelvis}

The CD fluid emerges into the pelvis where urea reflux into the papillary central core is allowed, thus favouring urea trapping in the inner medulla (Section 5). Consequently, the computed urea flow rate in the ureter is significantly lower than that in the papillary $C D$. This does not agree with experimental observations by Marsh and Martin (1980). However, these measurements were made in an exposed papilla and do therefore not agree with the assumptions of the present model. The computed values for the final urine concentrations are within the range of measurements for both salt and urea (Gunther and Rabinowitz, 1980; Forrest and Stanier, 1966).

\section{Variations of the Base Case}

\subsection{Alternative to OMCD Permeabilities}

In Section 3, the choice of OMCD permeabilities for water $\left(L p_{4}=48.4\right)$ and for urea $\left(P_{42}=0.097\right)$ in the base case has been discussed. Here, the results of the model with $L p_{4}=49.9$ (Horster and Zink, 1982) and $P_{42}=0.34$ (Rocha and Kokko, 1974) are presented. All other parameters remained unchanged. Figure 5.1 shows the computed concentration profiles for urea. As the salt concentrations did not change very much, characteristic values only are presented together with (TF/P) inulin ratios in Table 5.1. 
Fig. 5.1. Computed urea concentrations for $L p_{4}=49.9$ and $P_{42}=0.34$ (alternative to OMCD permeabilities) in DLH, ALH (- - - ) in CD, CC $(-)$ and in pelvis (*)

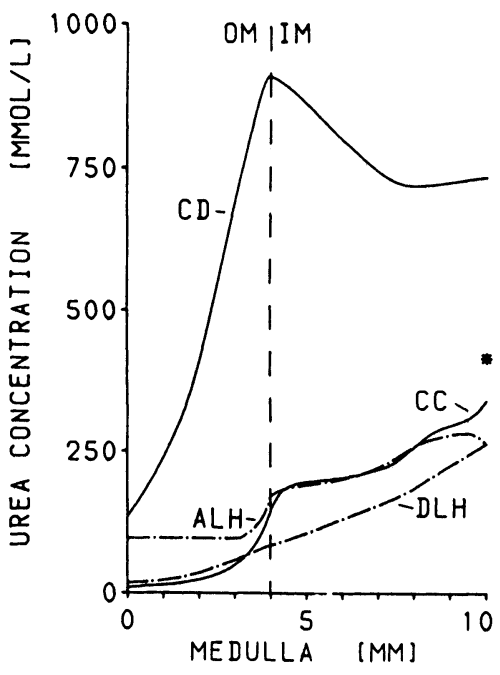

Table 5.1. Results for $L p_{4}=49.9$ and $P_{42}=0.34$ (alternative to $O M C D$ permeabilities). In each pair the first value gives the salt concentration $(\mathrm{mMol} / \mathrm{l})$ and the second value the $(\mathrm{TF} / \mathrm{P})$ ratio for inulin

\begin{tabular}{rrrrr}
\hline & DLH & ALH & CD & CC \\
\hline$x=0$ & 140.00 & 28.43 & 23.46 & 140.00 \\
& 3.00 & 14.92 & 30.10 & \\
$x=4$ & 693.99 & 653.46 & 239.97 & 662.13 \\
& 15.66 & 17.96 & 307.91 & \\
$x=10$ & 886.25 & 886.25 & 512.65 & 844.86 \\
& 22.24 & 22.24 & 657.78 & \\
\hline
\end{tabular}

Whereas the concentrations of both solutes still rise considerably along the inner medulla, the pattern of urea in the $C D$ is not satisfactory. The increase in OMCD urea permeability influences the urea permeability in the transition zone $4.0 \leqslant x \leqslant 7.0$. As a consequence, more urea than in the base case leaves the $C D$ in this region and the IMCD urea concentration falls from $908 \mathrm{mMol} / \mathrm{l}$ at the outerinner medullary junction to $734 \mathrm{mMol} / \mathrm{l}$ at the papillary tip. This is in contradiction to experimental results of Klümper et al. (1958). In the base case, a small net increase of urea concentration along the IMCD occurs.

\subsection{Pelvic Water Reflux}

As discussed in Section 3, a negligibly low water conductivity $\left(L p_{5}\right)$ between the pelvis and the papillary $C C$ was assumed in the base case. In the present simulation study this parameter is increased to 30 . Figure 5.2 displays the concentrations in the final urine and the increase of solute concentrations in the $\mathrm{CC}$ (the 


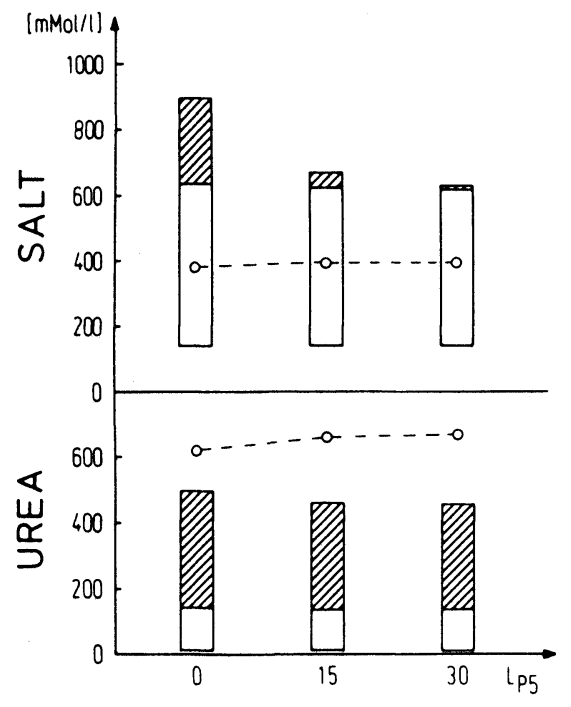

Fig. 5.2. Influence of pelvic water conductivity on concentration ability for salt (above) and urea (below): Final urine concentration $\left(\mathrm{O}^{---} \mathrm{O}\right)$ and increase of CC-concentration in the OM $(\square)$ and in the IM (团) for various values of $L p_{5}$. Base of columns corresponds to corticomedullary interstitial concentration

Table 5.2. Osmolarity of the fluid in the $C D$ at the papillary tip (upper value) and of pelvic urine (lower value) for various values of $L p_{5}$ and $P_{52}$

\begin{tabular}{lrrrr}
\hline$P_{52}=30 ;$ & $L p_{5}=$ & 0 & 15 & 30 \\
Osmolarity (mOsm/l): & & 1712 & 1474 & 1441 \\
& & 1312 & 1369 & 1385 \\
\hline$L p_{5}=0 ;$ & $P_{52}=$ & 0 & 15 & 30 \\
Osmolarity $(\mathrm{mOsm} / \mathrm{l}):$ & & 1445 & 1657 & 1712 \\
& & 1445 & 1349 & 1312 \\
\hline
\end{tabular}

main contribution to the slice concentrations) along both the outer and the inner medulla for various values of $L p_{5}$. While the pattern of urea is rather constant, the salt concentration profile in the inner medullary $C C$ becomes very flat for nonvanishing values of $L p_{5}$. The stability of CC urea and the depression of CC salt concentration is due to the fact that the pelvic reabsorbate contains urea but no salt. Table 5.2 (upper panel) shows the reduction of osmolarity as the fluid empties from the end of the $\mathrm{CD}$ into the pelvis.

\subsection{Pelicic Urea Reflux}

Due to morphologic arguments, a rather high permeability for entry of pelvic urea into the papillary CC was used in the base case $\left(P_{52}=30\right)$. The effect of decreasing this parameter to zero is shown in Table 5.2 and Fig. 5.3. In the final urine, salt concentration remains rather constant whereas urea concentration rises as expected. But more remarkable is the result that for vanishing urea permeability the CC concentration for both salt and urea remains almost constant at the level that 
Fig. 5.3. Influence of pelvic urea permeability on

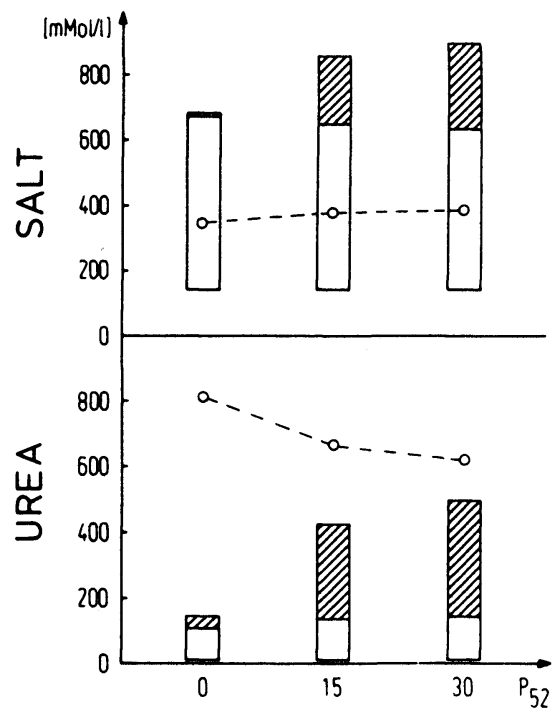
concentration ability for salt (above) and urea (below): Final urine concentration $(\mathrm{O}---\mathrm{O})$ and increase of CC-concentration in the OM $(\square)$ and in the IM (团) for various values of $P_{52}$

was reached at the outer-inner medullary junction. Hence, pelvic urea reentry supports both salt and urea trapping in the inner medullary CC. The possibility of this mechanism has previously been alluded to, however, without proof by model simulation (Chandhoke and Saidel, 1981).

\subsection{Collecting Duct Architecture}

The base case reflects a physiologically realistic CD-structure: $512 \mathrm{CD}$ merge into one (see Section 3). Two variations of this case were studied: Simulation $S_{1}$ has

Fig. 5.4. Influence of CD-geometry on concentration ability for salt (above) and urea (below): Final urine concentration $\left(\mathrm{O}_{---} \mathrm{O}\right)$ and increase of CC-concentration in the OM $(\square)$ and in the IM (四) for various CD-geometries (see text)

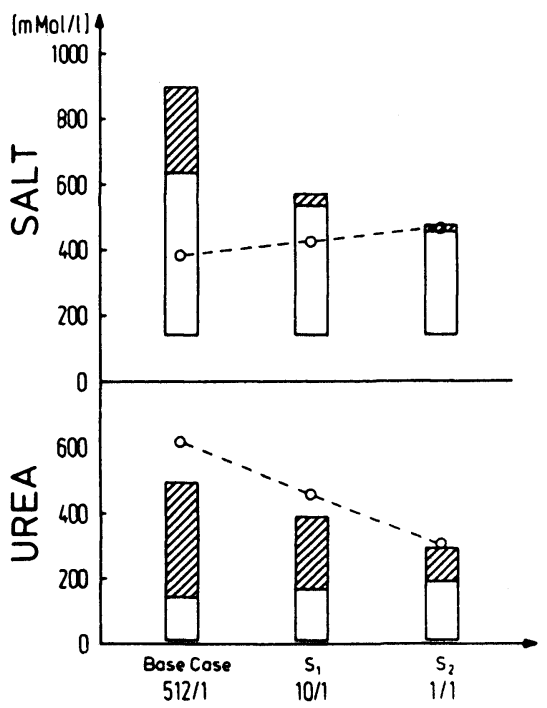


studied a reduced CD-architecture: $10 \mathrm{CD}$ merge into one. In simulation $S_{2}$ any CD geometry is absent and $\operatorname{NCD}(x)$ is constant. In both $S_{1}$ and $S_{2}$, the approximate doubling of the radius of a single $\mathrm{CD}$ (see Section 3 ) has been neglected in order to make the results more comparable to previous models.

Figure 5.4 demonstrates that the absence of a CD architecture $\left(S_{2}\right)$ produces unphysiologically low urea concentrations in the final urine. For the CC, Fig. 5.4 shows the strong impact of the $\mathrm{CD}$ structure on the inner medullary concentration gradient.
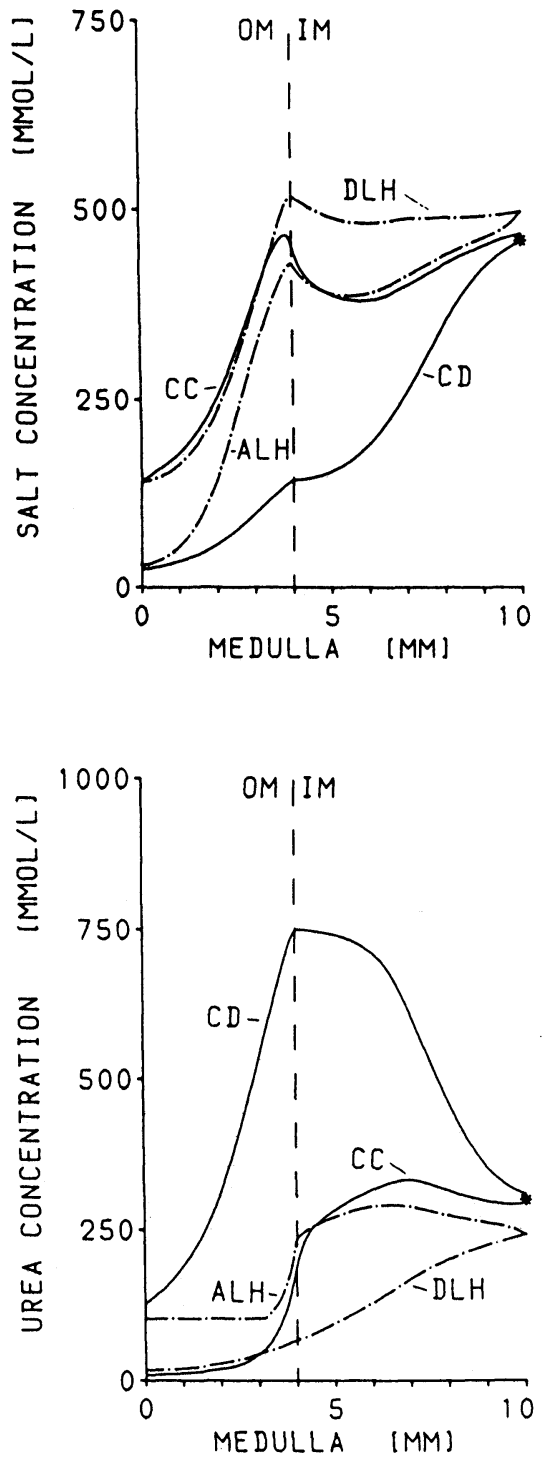

Fig. 5.5. Computed salt concentrations for simulation $S_{2}$ (absence of CD-geometry) in DLH, ALH (--) ), in CD, CC (-) and in pelvis (*)

Fig. 5.6. Computed urea concentrations for simulation $S_{2}$ (absence of CD-geometry) in DLH, ALH (- - - ), in CD, CC (-) and in pelvis (*) 
Obviously then, the CD geometry, as existing in the medulla, is an important determinant of a strong concentration gradient along the length of the inner medullary CC.

Figures 5.5 and 5.6 display the concentration profiles resulting from simulation $S_{2}$. They follow the same patterns as those computed for the rabbit case by Foster and Jacquez (1978): No substantial rise in solute concentration along the inner medulla, equilibration of the CD fluid with the other structures for both salt and urea at the papilla, low urea concentration in the final urine, and a precipitous fall of IMCD urea concentration. A comparison with the base case reveals that incorporation of the morphologically realistic CD-geometry is essential for the design of kidney models, in order to produce results closer to physiological data obtained in tissue slice and micropuncture studies.

\section{Conclusions}

The simulations described in the previous section show that the parameters for pelvic reflux in the base case favour urea trapping in the inner medulla. Because of the exponentially decreasing effective surface area per unit length of the CDsystem, the high urea concentration in the $C D$ at the outer-inner medullary junction is maintained against the relatively low urea concentration in the surrounding CC, although the highest measured urea permeability value (Rocha and Kokko, 1974) was used. More than one half $(53 \%)$ of the IMCD urea load reaches the pelvis. From there, $39 \%$ of the pelvic urea load flows passively into the papillary CC. This urea delivery to the papillary CC is decisive for the generation of a strong positive concentration gradient along the length of the inner medulla. Although these features of the model favour urea trapping in the inner medulla which is a characteristic of the scheme of Kokko and Rector (1972), their a priori assumptions are not supported by the results of the model. In particular, their assumed value for urea concentration in the interstitium at the outer-inner medullary junction is much higher than predicted by any previous and the present mathematical model. Furthermore, it far exceeds what has been found by tissue analysis (see Moore and Marsh, 1980).

The present model utilizes those parameters which have been measured experimentally (except for the idealization inherent in the use of the central core). It demonstrates that a passive mode is capable of generating concentration profiles that are consistent with tissue slice measurements. In particular, it can produce a considerable increase in CC-concentrations for both salt and urea along the length of the inner medulla.

The results show that the geometry of the $\mathrm{CD}$ system is an important determinant of the inner medullary osmotic concentrating ability. In addition, the simulation studies ascribe a central role to pelvic urea for the generation of the inner medullary longitudinal osmotic gradient. While several experiments support this conclusion (Gertz et al., 1966; Schmidt-Nielsen et al., 1970, 1980; Bonventre et al., 1980) the magnitude of urea or water reentry from pelvis to papillary interstitium has never been quantified. Recently developed techniques to measure CD fluid composition through the intact ureter (Oliver et al., 1982) should be able to determine the difference in osmolarity between the fluid in the papillary $\mathrm{CD}$ and in 
the pelvis. A comparison of these measurements with the predictions of the present simulation studies would allow conclusions about the nature of the pelvic reabsorbate and its role for the concentrating mechanism.

Acknowledyements. The authors wish to thank Professor Dr. R. Bulirsch who has encouraged this work. They are indebted to Dr. L. C. Moore (Health Sciences Center of the State University of New York at Stony Brook) for many helpful discussions and suggestions.

\section{References}

Al-Zahid, G., Schafer, J. A., Troutman, S. L., Andreoli, T. E.: The effect of antidiuretic hormone in water and salt permeation, and the activation energies for these processes, in mammalian cortical collecting tubules. Evidence for parallel ADH-sensitive pathways for water and solute diffusion in luminal plasma membranes. J. Membrane Biol. 31, 103-129 (1977)

Beck, F., Dotzel, W., Rick, R., Dörge, A., Thurau, K.: Electron microprobe analysis of cellular element concentration in rat renal papilla during different states of diuresis (Abstract). Pflügers Arch. 391, $67(1981)$

Bonventre, J. V., Lechene, C.: Renal medullary concentrating process: An integrative hypothesis. Am. J. Physiol. 239, F578-F588 (1980)

Bonventre, J. V., Karnovsky, M. J., Lechene, C. P.: Renal papillary epithelial morphology in antidiuresis and water diuresis. Am. J. Physiol. 235, F69-F76 (1978)

Bonventre, J. V., Roman, R. J., Lechene, C.: Effect of urea concentration of pelvic fluid on renal concentration ability. Am. J. Physiol. 239, F609-F618 (1980)

Bulger, R. E., Beeuwkes III, R., Saubermann, A. J.: Application of scanning electron microscopy to $\mathrm{x}$-ray analysis of frozen-hydrated sections. III. Elemental content of cells in the rat renal papillary tip. J. Cell. Biol. 88, 274-280 (1981)

Bulirsch, R.: Die Mehrzielmethode zur numerischen Lösung von nichtlinearen Randwertproblemen und Aufgaben der optimalen Steuerung. Report of the Carl-Cranz-Gesellschaft, 1971

Burg, M., Green, N.: Function of the thick ascending limb of Henle's loop. Am. J. Physiol. 224, $658-659(1973)$

Burg, M., Helman, S., Grantham, J., Orloff, J.: Effect of vasopressin on the permeability of isolated rabbit cortical collecting tubules to urea, acetamide, and thiourea. In: Urea and the kidney (Schmidt-Nielsen B., Kerr, D. W. S., eds.), pp. 193-199. Amsterdam: Excerpta Medica 1970

Capek, K., Fuda, G., Rumrich, G., Ullrich, K. J.: Harnstoffpermeabilität der corticalen Tubulusabschnitte von Ratten in Antidiurese und Wasserdiurese. Pflügers Arch. 290, 237-249 (1966)

Chandhoke, P. S., Saidel, G. M.: Mathematical model of mass transport throughout the kidney: Effects of nephron heterogeneity and tubular-vascular organization. Ann. Biomed. Eng. 9, 263-301 (1981)

Deuflhard, P.: A relaxation strategy for the modified Newton method. In: Optimization and Optimal Control (Bulirsch, R., Oettli, W., Stoer, J., eds.), pp. 59-73, Lecture Notes in Mathematics, Vol. 477. Berlin-Heidelberg-New York: Springer 1975

Fehiberg, E.: Klassische Runge-Kutta-Formeln fünfter und siebenter Ordnung mit Schrittweitenkontrolle. Computing 4, 93-106 (1969)

Forrest, J. N., Jr., Stanier, M. W.: Kidney composition and renal concentration ability in young rabbits. J. Physiol. 187, I-4 (1966)

Foster, D. M., Jacquez, J. A. : Comparison using central core model of renal medulla of the rabbit and the rat. Am. J. Physiol. 234, F402-F414 (1978)

Fourman, J., Moffat, D. B.: The blood vessels of the kidney. Oxford-Edinburgh: Blackwell Sci. Publ. 1971

Frindt, G., Burg, M. W. : Effect of vasopressin on sodium transport in renal cortical collecting tubules. Kidney Int. 1, 224-231 (1972)

Gertz, K. H., Schmidt-Nielsen, B., Pagel, H. D.: Exchange of water, urea and salt between the mammalian renal papilla and the surrounding urine (Abstract). Federation Proc. 25, 327 (1966) 
Gottschalk, C., Mylle, M.: Micropuncture study of the mammalian urinary concentrating mechanism: Evidence for the countercurrent hypothesis. Am. J. Physiol. 196, 927-936 (1959)

Gunther, R. A., Rabinowitz, L.: Urea and renal concentrating ability in the rabbit. Kidney Int. 17, $205-222(1980)$

Hai, M. A., Thomas, S.: The time-course of changes in renal tissue composition during lysine vasopressin infusion in the rat..Pflügers Arch. 310, 297-319 (1969)

Hilger, H. H., Klümper, J. D., Ullrich, K. J.: Wasserrückresorption und Ionentransport durch die Sammelrohrzellen der Säugetierniere. Pflügers Arch. 267, 218-237 (1958)

Horster, M., Zink, H.: Functional differentiation of the medullary collecting tubule: Influence of vasopressin. Kidney Int. 22, 360-365 (1982)

Imai, M., Kokko, J. P.: Sodium chloride, urea and water transport in the thin ascending limb of Henle: Generation of osmotic gradients by passive diffusion of solutes. J. Clin. Invest. 53, 393-402 (1974)

Jacquez, J. A., Foster, D., Daniels, E.: Solute concentration in the kidney-1. A model of the renal medulla and its limit cases. Math. Biosci. 32, 307-335 (1976)

Jamison, R. L., Robertson, C. R.: Recent formulations of the urinary concentrating mechanism: A status report. Kidney Int. 16, $537-545$ (1979)

Johnston, P. A., Battilana, C. A., Lacy, F. B., Jamison, R. L.: Evidence for a concentration gradient favouring outward movement of sodium from the thin loop of Henle. J. Clin. Invest. 59, 234-240 (1977)

Kainer, R.: A geometric model of the rat kidney. Anat. Embryol. 147, 91 - 109 (1975)

Kaissling, B. : Ultrastructural characterization of the connecting tubule and the different segments of the collecting duct system in the rabbit kidney. In: Biochemical nephrology (Guder, W., Schmidt, U., eds.), pp. 99 - 119. Bern: Huber 1978

Kaissling, B., Kriz, W.: Structural analysis of the rabbit kidney. Berlin-Heidelberg-New York : Springer 1979

Klümper, J. D., Ullrich, K. J., Hilger, H. H.: Das Verhalten des Harnstoffs in den Sammelrohren der Säugetierniere. Pflügers Arch. 267, $238-243$ (1958)

Knepper, M. A., Danielson, R. A., Saidel, G. M., Post, R. S. : Quantitative analysis of renal medullary anatomy in rats and rabbits. Kidney Int. 12, 313-323 (1977)

Koepsell, H., Nicholson, W. A. P., Kriz, W., Höhling, H. J.: Measurements of exponential gradients of sodium and chloride in the rat kidney medulla using the electron microprobe. Pflügers Arch. 350, $167-184$ (1974)

Kokko, J. P.: Sodium chloride and water transport in the descending limb of Henle. J. Clin. Invest. 49, $1838-1846(1970)$

Kokko, J. P.: Urea transport in the proximal tubule and the descending limb of Henle. J. Clin. Invest. 51, $1999-2008$ (1972)

Kokko, J. P., Rector, F. C., Jr.: Countercurrent multiplication system without active transport in inner medulla. Kidney Int. 2, 214-233 (1972)

Kriz, W.: Der architektonische and funktionelle Aufbau der Rattenniere. Z. Zellforsch. Mikrosk. Anat. 82, 495-535 (1967)

Kriz, W.: Structural organization of the renal medulla: Comparative and functional aspects. Am. J. Physiol. 241, R3-R16 (1981)

Kuhn, W., Ryffel, K.: Herstellung konzentrierter Lösungen aus verdünnten durch bloße Membranwirkung. Ein Modellversuch zur Funktion der Niere. Hoppe-Seylers Z. Physiol. Chem. 276, $145-178$ (1942)

Lassiter, W. E., Frick, A., Rumrich, G., Ullrich, K. J.: Influence of ionic calcium on the water permeability of proximal and distal tubules in the rat kidney. Pflügers Arch. 285, 90-95 (1965)

Laurence, R., Marsh, D. J.: Effect of diuretic states on hamster collecting duct electrical potential differences. Am. J. Physiol. 220, 1610-1616 (1971)

Lory, P.: Numerical solution of a kidney model by multiple shooting. Math. Biosci. 50, 117-128 (1980)

Lory, P., Gilg, A., and Horster, M.: Computation of renal osmotic work in a "passive" central core model incorporating medullary geometry and pelvic urea reflux (Abstract). Pflügers Arch. 391, R27 (1981)

Marsh, D. J.: Solute and water flows in thin limbs of Henle's loop in the hamster kidney. Am. J. Physiol. 218, 824-831 (1970)

Marsh, D. J., Martin, C. M.: Lack of water or urea movement from pelvic urine to papilla in hydropenic hamsters. Mineral Electrolyte Metab. 3, 81 - 86 (1980) 
Marsh, D. J., Kelman, R. B., Howard, H. C.: The theory of urine formation in water diuresis with implications for antidiuresis. Bull. Math. Biophys. 29, 67-89 (1967)

Mejia, R., Stephenson, J. L. : Numerical solution of multinephron kidney equations. J. Comp. Phys. 32, $235-244$ (1979)

Moore, L. C., Marsh, D. J.: How descending limb of Henle's loop permeability affects hypertonic urine formation. Am. J. Physiol. 239, F57-F71 (1980)

Oberle, H. J.: Numerische Berechnung optimaler Steuerungen von Heizung und Kühlung für ein realistisches Sonnenhausmodell. Habilitationsschrift. Technische Universität, München, 1982

Oliver, J.: Nephrons and kidneys. New York: Hoeber Medical Division 1968

Oliver, R. E., Roy, D. R., Jamison, R. L.: Urinary concentration in the papillary collecting duct of the rat. Role of the ureter. J. Clin. Invest. 69, 157-164 (1982)

Pennell, J. P., Sanjana, V., Frey, N. R., Jamison, R. L.: The effect of urea infusion on the urinary concentrating mechanism in protein-depleted rats. J. Clin. Invest. 55, 399-409 (1975)

Rocha, A., Kokko, J. P.: Sodium chloride and water transport in the medullary thick ascending limb of Henle. J. Clin. Invest. 52, 612-623 (1973)

Rocha, A. S., Kokko, J. P.: Permeability of medullary nephron segments to urea and water: Effect of vasopressin. Kidney Int. 6, $379-387$ (1974)

Roch-Ramel, F., Filloux, B., Guignard, J. P., Peters, G. : Fate of urea in Henle's loops of the rabbit and the rat. In.: New aspects of renal function (Vogel, H. G., Ullrich, K. J., eds.), pp. 118-121. Amsterdam: Excerpta Medica 1978

Schafer, J. A., Andreoli, T. E.: The effect of antidiuretic hormone on solute flows in mammalian collecting tubules. J. Clin. Invest. 51, $1279-1286$ (1972)

Schmidt-Nielsen, B., Pagel, H. D.: Mechanism of urea retention in the renal medulla. In: Urea and the kidney (Schmidt-Nielsen, B., Kerr, D. W. S., eds.), pp. 393-400. Amsterdam: Excerpta Medica 1970

Schmidt-Nielsen, B., Churchill, M., Reinking, L. N.: Occurrence of renal pelvic refluxes during rising urine flow rate in rats and hamsters. Kidney Int. 18, 419-431 (1980)

Schütz, W., Schnermann, J.: Pelvic urine composition as a determinant of inner medullary solute concentration and urine osmolarity. Pflügers Arch. 334, 154-166 (1972)

Sperber, I.: Studies on the mammalian kidney. Zool. Bidr. Uppsala 22, 249-431 (1944)

Stephenson, J. L.: Concentration of urine in a central core model of the renal counterflow system. Kidney Int. 2, 85-94 (1972)

Stephenson, J. L. : The mathematical theory of renal function. In : Engineering Principles in Physiology (Brown, J. H. U., Gann, D. S., eds.), vol. 2, pp. 283-320. New York, London: Academic Press 1973

Stephenson, J. L., Tewarson, R. P., Mejia, R.: Quantitative analysis of mass and energy balance in nonideal models of the renal counterflow system. Proc. Nat. Acad. Sci. USA 71, 1618-1622 (1974)

Stephenson, J. L., Mejia, R., Tewarson, R. P.: Model of solute and water movement in the kidney. Proc. Nat. Acad. Sci. USA 73, $252-256$ (1976)

Stoer, J., Bulirsch, R.: Introduction to numerical analysis. New York: Springer 1980

Ullrich, K. J., Hilger, H. H., Klümper, J. D.: Sekretion von Ammoniumionen in den Sammelrohren der Säugetierniere. Pflügers Arch. 267, 244-250 (1958)

Ullrich, K. J., Rumrich, G., Baldamus, C. A.: Mode of urea transport across the mammalian nephron. In: Urea and the kidney (Schmidt-Nielsen, B., Kerr, D. W. S., eds.), pp. 175-185. Amsterdam: Excerpta Medica 1970

Ullrich, K. J., Rumrich, G., Fuchs, G. : Wasserpermeabilität und transtubulärer Wasserfluß cortikaler Nephronabschnitte bei verschiedenen Diuresezuständen. Pflügers Arch. 280, 99 - 119 (1964)

Received July 5/Revised September 28, 1982 